\title{
MATHEMATICAL SIMULATION OF CONVECTIVE HEAT TRANSFER IN THE LOW-TEMPERATURE STORAGE OF LIQUEFIED NATURAL GAS
}

\author{
Igor A. Shestakov ${ }^{1}$, Anastasia A. Dolgova ${ }^{1}$, Vyacheslav I. Maksimov ${ }^{1 a}$ \\ ${ }^{1}$ National Research Tomsk Polytechnic University, 634050 Tomsk, Russia
}

\begin{abstract}
The article shows the results of mathematical modeling of convective heat transfer in the low-temperature storage of liquefied natural gas. Regime of natural convection in an enclosure with different intensity of the heat flux at the external borders are investigated. Was examined two-dimensional nonstationary problem within the model of Navier-Stokes in dimensionless variables "vorticity - stream function - temperature". Distributions of hydrodynamic parameters and temperatures that characterize the basic regularities of the processes are obtained. Circulating flows are determined and carried out the analysis of vortices formation mechanism and the temperature distribution in solution at conditions of natural convection when the Grashof number $\left(\mathrm{Gr}=10^{6}\right)$. A significant influence of heat transfer rate on solutions boundary on flow structure and temperature field in LNG storage tanks.
\end{abstract}

\section{Introduction}

The study of heat transfer in the storage of liquefied natural gas (LNG) is great importance for modeling and optimization of the physical processes associated with its production, storage and transport [1-3]. The increase in production of liquefied natural gas leads to an increase in the volume of tanks for storage. The intensity of the heat flow through the walls of LNG storage may be quite varied in different range, both depending on the climatic conditions, and depending on the insulating shells in the event of emergencies, such as fire or depressurization of vacuum insulation repository [45]. Uneven heat flow at the external borders of the low-temperature storage tank could lead to a global change in the thermal regime in it (for example, the phenomenon - Rollover) [4-7] and cause major technological accident.

Objective: mathematical modeling of unsteady convective heat transfer in low-temperature tanks storage of LNG, taking into account the external thermal insulation heat leakage circuit.

\section{Problem Statement and the Method for the Solution}

\footnotetext{
${ }^{a}$ Corresponding author : elf@tpu.ru
} 
The flow of viscous incompressible fluid and heat transfer in a rectangular closed region (Fig. 1). It is assumed that the thermal properties of the medium does not depend on the temperature and the flow regime is laminar. Modeling of free-convection heat transfer in fluid was carried out in range of Grashof number $\mathrm{Gr}=10^{3} \div 10^{6}$, which corresponds to the laminar flow. The fluid is considered Newtonian incompressible and satisfies the Boussinesq approximation. It should be noted that the movement of the heat transfer fluid in the cavity and are received by two-dimensional, radiation heat transfer - is negligibly small compared to the convective heat transfer, and the liquid is absolutely transparent to thermal radiation. The process of heat transfer in the field of system solutions describe unsteady two-dimensional equations of convection in the Boussinesq approximation [8]. The dimensionless Navier-Stokes equations in «vorticity - stream function - the temperature» for the problem have the form:

$$
\begin{gathered}
\frac{1}{\mathrm{Sh}} \frac{\partial \Omega}{\partial \tau}+U \frac{\partial \Omega}{\partial X}+V \frac{\partial \Omega}{\partial Y}=\frac{1}{\sqrt{\mathrm{Gr}}} \Delta \Omega+\frac{1}{2} \frac{\partial \Theta}{\partial X} \\
\Delta \Psi=-2 \Omega \\
\frac{1}{\mathrm{Sh}} \frac{\partial \Theta}{\partial \tau}+U \frac{\partial \Theta}{\partial X}+V \frac{\partial \Theta}{\partial Y}=\frac{1}{\operatorname{Pr} \sqrt{\mathrm{Gr}}} \Delta \Theta 1
\end{gathered}
$$

At the upper limit given by the condition of the free surface, where due to the evaporation of the liquid is carried out additional heat dissipation. On the other boundaries set by the heat flux. It is assumed that initially the liquid is stationary and has the same temperature throughout the study area.

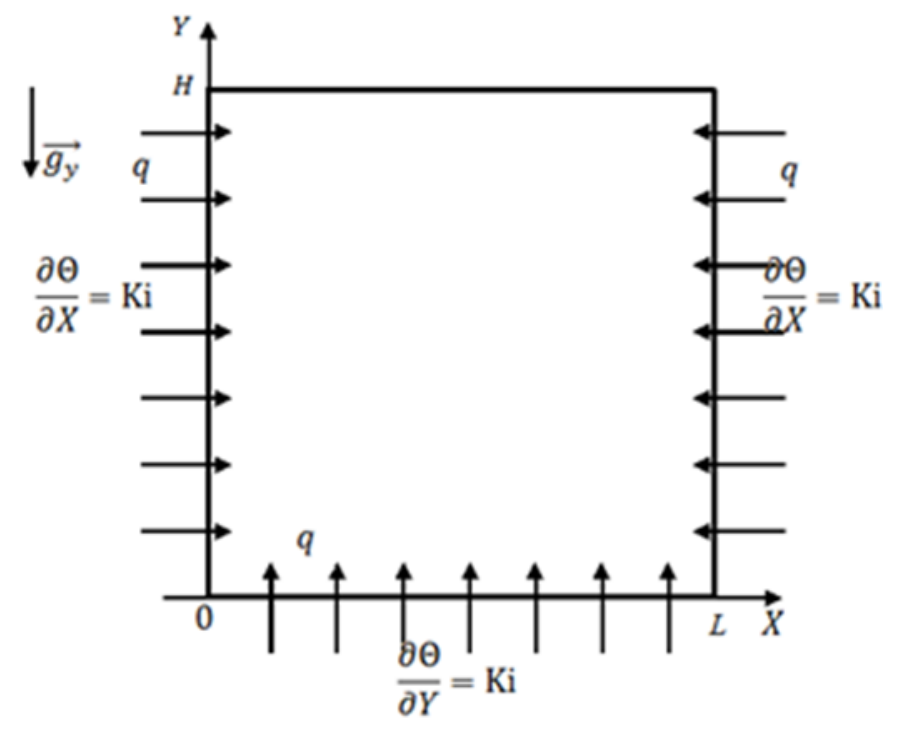

Figure 1. A scheme of the system

The system of differential equations with appropriate initial and boundary conditions was solved by finite difference method. In solving algorithm was used [9-11] developed for the numerical solution of natural convection in a closed rectangular areas with local sources of energy.

\section{The results of numerical modeling}


Numerical analysis of the basic laws was carried out the following values of the dimensionless quantity: $10^{4}<\mathrm{Gr}<10^{6}$. Figure 2 shows the contour function of current and temperature field in the LNG storage tank at different thermal loads on the external borders of the study area.

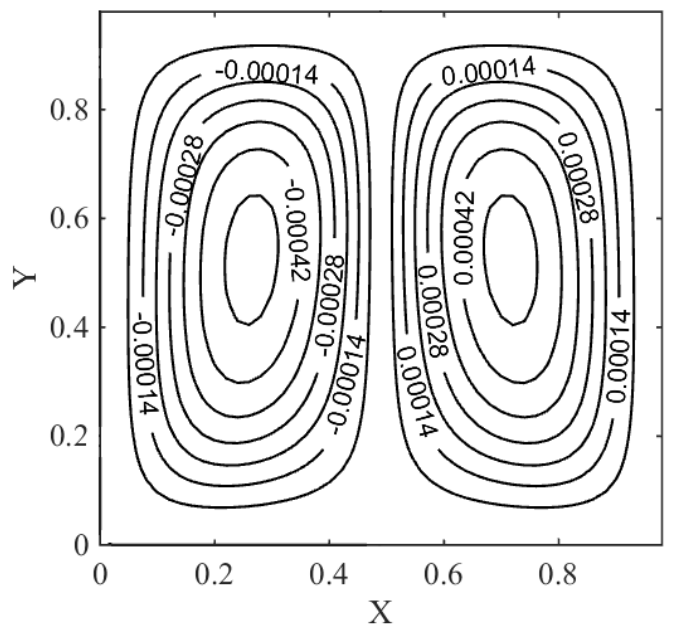

(a)

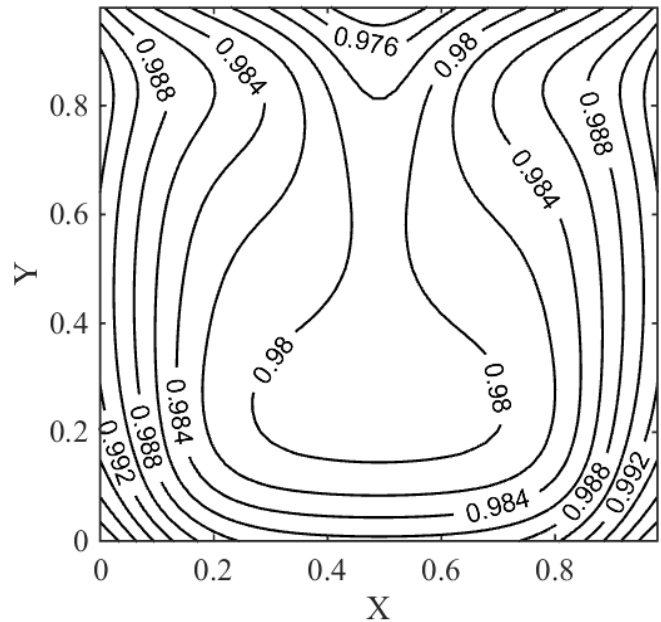

(c)

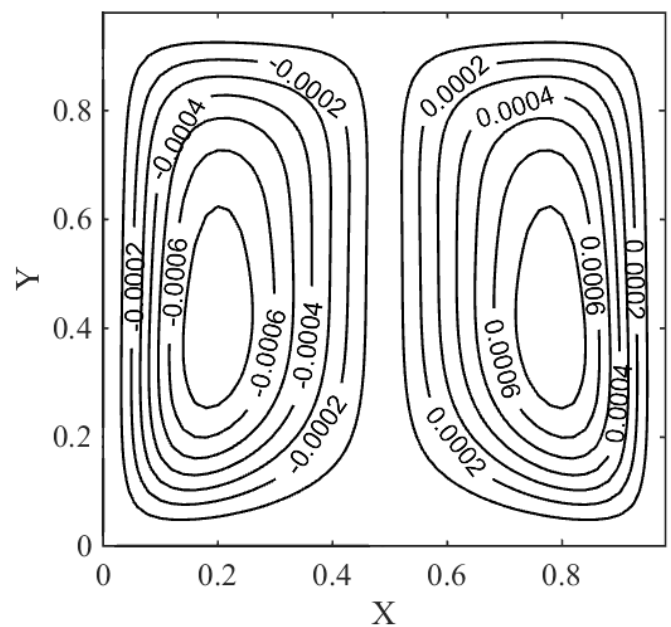

(b)

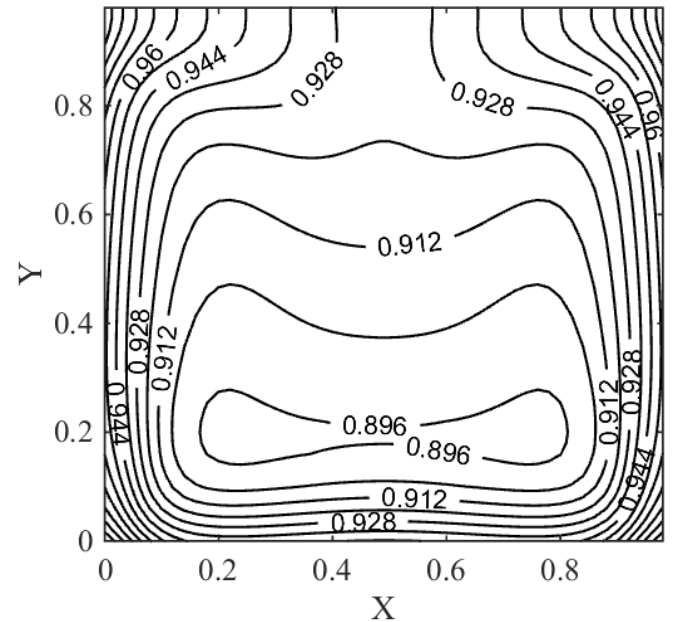

(d)

Figure 2. The isolines of stream function $(a, b)$, and the temperature field $(c, d)$ in the LNG tanks at various heat flux on the boundaries: a, c) $\left.q=0.05 \mathrm{~W} / \mathrm{m}^{2}, \mathrm{~b}, \mathrm{~d}\right) \mathrm{q}=0.4 \mathrm{~W} / \mathrm{m}^{2}$

Forming a stable fluid flow pattern in the test area to form two symmetrical vortices. The increase in the heat flux density at the external borders raises the temperature in the wall region and an increase in the fluid velocity along these boundaries. Low temperatures in the upper surface layer of the liquid due to the intense heat sink due to evaporation at the upper boundary of the solution.

With the increase in the density of the heat flow through the external boundary of the solution increases the temperature gradient in the central section of the tank (Figure 3). Increasing the temperature at the bottom of the reservoir due to the heat supply fluid from the outer boundaries, whereas in the upper region of the temperature will not vary significantly as the heat gain is partially offset by the heat removal by evaporation from the free surface of the liquid. 


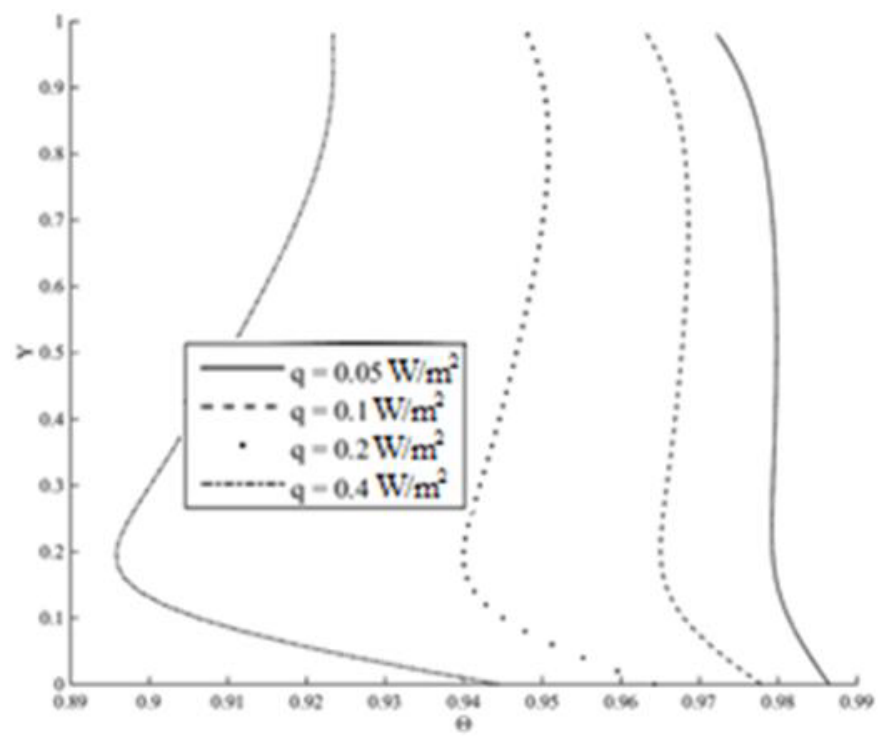

Figure 3. The temperature profile along the vertical in the central section of the area under consideration $(X=$ $0.5,0 \leq Y \leq 1))$

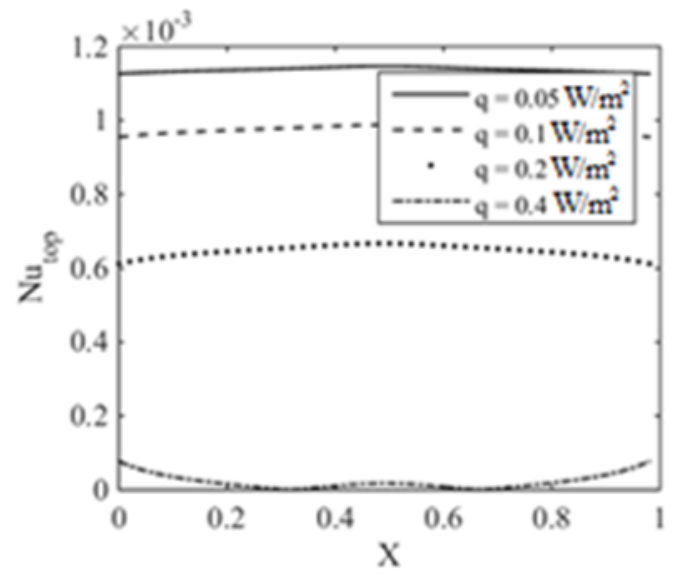

(a)

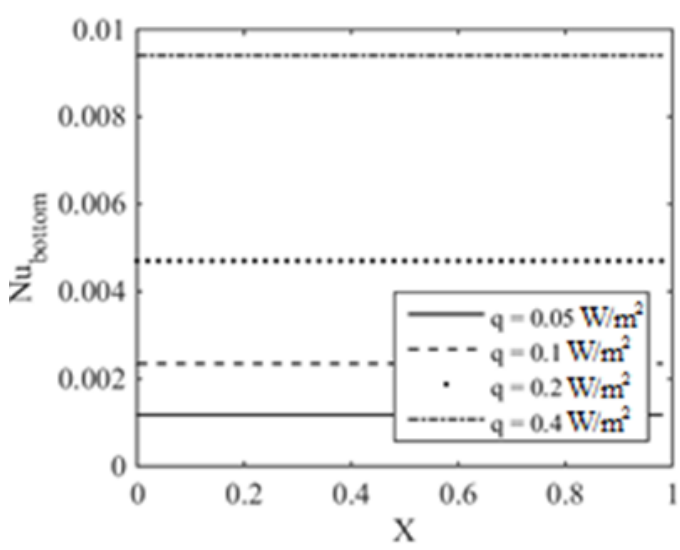

(b)

Figure 4. Distribution of Nusselt number on borders: a) $0 \leq X \leq 1, Y=1$, b) $0 \leq X \leq 1, Y=0$

The intensity of the heat transfer at the boundaries (Fig. 4 b) is constant along the perimeter of the study area, except for the upper limit of which there is an additional heat by evaporation of the liquid. The heated fluid, moving up along the vertical boundaries and increases the heat transfer rate at the peripheral border, and moving closer to the center region, its cooling takes place, thereby reducing the heat in this area of the boundary of solutions. $\mathrm{W} / \mathrm{m}^{2}$.

\section{Conclusion}

The influence of different intensity of heat exchange on the boundaries of low-temperature storage tank to the convection regimes of liquefied natural gas is theoretically investigated. The obtained theoretical consequences give the new information, which not only characterizes convective flow 
conditions, but also it is additional for construction and approval of the models of the free convection of liquefied natural gas.

The results of work show the possibility of using the Navier-Stokes equations in the variables «vorticity - stream function» for the simulation of fairly complicated by nature flows with the moderate values of the Grashof numbers in the regime of free convection and with the heterogeneous heat exchange on the outer boundaries of solution region.

Is revealed the significant influence of the intensity of uneven heat exchange on the boundaries of solution region to the flow conditions and the temperature distribution in the liquid being investigated. For example, an increase in the heat flux density at the boundary of solutions of $0.1 \mathrm{~W} / \mathrm{m}^{2}$ leads to an increase of the temperature gradient over the depth of the tank at $0.05 \mathrm{~K}$. Based on these results it can be concluded that by adjusting the heat transfer rate at the boundaries of the low-temperature storage tank can be controlled thermal conditions of the liquefied gas in implementing it in free convection.

The work was realized within the research state assignment "Science” №13.1339.2014/K (Code of Federal Target Scientific and Technical Program 2.1410.2014).

\section{References}

1. Bin Xu, Yumei Shi, Dongsheng Chen, Cryogenics, 60, 68 (2014)

2. M.W. Lukaszewski, W.B.J. Zimmerman, M.T. Tennant, Chem. Eng. Res. Des. 91, 3 (2013)

3. Calogero Migliore, Cristina Tubilleja, Velisa Vesovic, J. Nat. Gas Sci. Eng., 26, 570 (2015)

4. O.N. Aneziris, I.A. Papazoglou, M. Konstantinidou, Z. Nivolianitou, J. Loss. Prevent. Proc., 28, $23(2014)$

5. J.Q. Shi, C. Beduz, R.G. Scurlock, Cryogenics, 33, 12 (1993)

6. Yuxing Li, Zhenglong Li, Wuchang Wang, J. Loss. Prevent. Proc., 37, 132 (2015)

7. Lu, X.S., Lin, W.S., Gu, A.Z., Qin, Z.H., Numerical modeling of stratification and rollover in LNG and the improvements to Bates-Morrison Model. (In: Proceedings of the 6th ASME-JSME Thermal Engineering Joint Conference, Kohala Coast, Hawaii, 2003)

8. I.A. Belov, S.A. Isaev, Modeling of turbulent flows: Textbook (St. Petersburg, Baltic State Technical University, 2001)

9. G.V. Kuznetsov, N.I. Kurilenko, V.I. Maksimov, G.Ya. Mamontov, T.A. Nagornova, Journal of Engineering Physics and Thermophysics, 86, 3 (2013)

10. G.V. Kuznetsov, M.A. Sheremet, Thermophysics and Aeromechanics, 16, 1 (2009)

11. V. I. Maksimov, T.A. Nagornova, EPJ Web of Conferences, 76, (2014) 